Nova Prasela ${ }^{1}$

Ramdhan Witarsa ${ }^{2}$

Dedi Ahmadi ${ }^{3}$

\section{KAJIAN LITERATUR TENTANG HASIL BELAJAR KOGNITIF MENGGUNAKAN MODEL PEMBELAJARAN LANGSUNG SISWA SEKOLAH DASAR}

\begin{abstract}
Abstrak
Penelitian ini bertujuan untuk mendeskripsikan kajian literatur tentang hasil belajar kognitif menggunakan model pembelajaran langsung pada siswa sekolah dasar. Metode penelitian ini menggunakan kajian literatur. Sumber data penelitian berupa artikel-artikel jurnal nasional dalam 5 tahun terakhir (2015-2020). Hasil penelitian menunjukkan bahwa dari 15 artikel didapatkan 4 artikel yang sesuai dengan topik judul. Dari ke 4 artikel tersebut, artikel yang membahas tentang hasil belajar kognitif dengan menerapkan 6 tingkatan terdapat 1 artikel. Artikel yang menerapkan C1 saja terdapat 1 artikel (artikel nomor 2). Artikel yang menerapkan C6 saja terdapat 1 artikel (artikel nomor 3), dan artikel yang menerapkan C4 dan C6 terdapat 1 artikel (artikel nomor 4). Artikel yang menerapkan langkah-langkah model pembelajaran langsung hanya 2 artikel, yaitu artikel nomor 1 dan 2. Artikel nomor 3 dan 4 tidak menjelaskan langkah-langkah model pembelajaran langsung. Model pembelajaran langsung dapat meningkatkan hasil belajar kognitif siswa sekolah dasar.
\end{abstract}

Kata Kunci: Kajian Literatur, Hasil Belajar Kognitif, Model Pembelajaran Langsung.

\begin{abstract}
This study aims to describe the literature review on cognitive learning outcomes using a direct learning model for elementary school students. This research method uses literature review. The data source of this research is national journal articles in the last 5 years (2015-2020). The results showed that from 15 articles, there were 4 articles about cognitive learning outcomes using the direct learning model of elementary school students. Of the 4 articles, the article that discusses cognitive learning outcomes by applying 6 levels contains 1 article. The article that applies C1 alone has 1 article (article number 2). Articles that apply C6 alone have 1 article (article number 3 ), and articles that apply C4 and C6 have 1 article (article number 4). Articles that apply the steps of the direct learning model are only 2 articles, namely articles number 1 and 2 . Articles number 3 and 4 do not explain the steps of the direct learning model. The direct learning model can improve the cognitive learning outcomes of elementary school students.
\end{abstract}

Keywords: Literature Review, Cognitive Learning Outcomes, Direct Learning Models.

\footnotetext{
${ }^{1}$ Program Studi PGSD, Fakultas Ilmu Pendidikan, Universitas Pahlawan Tuanku Tambusai novaprasela87@gmail.com

${ }^{2}$ Program Studi PGSD, Fakultas Ilmu Pendidikan, Universitas Pahlawan Tuanku Tambusai drdadan19@gmail.com

${ }^{3}$ Program Penjaskesrek, Fakultas Ilmu Pendidikan, Universitas Pahlwan Tuanku Tambusai ammardzoky@gmail.com
} 


\section{PENDAHULUAN}

Pendidikan sebagai suatu usaha untuk menjadikan kehidupan bangsa yang berkualitas dan bermanfaat. Manusia yang mempunyai kualitas akan menjadi salah satu aset yang berharga dalam lingkup pendidikan. Dalam Undang-Undang Sistem Pendidikan Nasional (UUSPN) Nomor 20 Tahun 2003 pasal 1 mendefinisikan pendidikan sebagai usaha sadar dan terencana untuk mewujudkan suasana belajar dan proses pembelajaran agar siswa secara aktif mengembangkan potensi dirinya untuk memiliki kekuatan spiritual keagamaan, pengendalian diri, kepribadian, kecerdasan, ahlak mulia, serta kemampuan yang diperlukan dirinya, masyarakat, bangsa, dan negara (Witarsa et al., 2020).

Belajar merupakan suatu proses yang ditandai dengan adanya perubahan pada diri seseorang sebagai hasil dari pengalaman dan latihan (Fatikasari et al., 2020). Perubahan sebagai hasil dari belajar dapat ditimbulkan dalam berbagai bentuk, seperti perubahan pengetahuan, pemahaman, sikap dan tingkah laku, kecakapan serta kemampuan. Apabila tidak terjadi perubahan dalam diri siswa, maka belajar dikatakan tidak berhasil. Keberhasilan siswa sangat dipengaruhi oleh kemampuan belajarnya dan faktor bimbingan dari guru atau kemauan siswa untuk belajar. Seorang guru selalu mengharapkan siswanya untuk mencapai hasil belajar yang baik (Mulyono et al., 2017).

Untuk mencapai hasil belajar yang baik tentu tidaklah mudah, guru sebagai pendidik berperan besar dalam proses pembelajaran. Guru harus merancang metode pembelajaran yang tepat dengan materi pelajaran yang bersumber dari kurikulum. Salah satu model yang tepat digunakan guru dalam pembelajaran adalah model pembelajaran langsung. Model pembelajaran langsung adalah salah satu pendekatan mengajar yang dirancang khusus untuk menunjang proses belajar siswa yang berkaitan dengan pengetahuan deklaratif dan pengetahuan prosedural yang terstruktur dengan baik yang dapat diajarkan dengan pola kegiatan bertahap, selangkah demi selangkah (Hamka \& Arsyad, 2007). Model pembelajaran langsung ditunjukan pula untuk membantu siswa mempelajari keterampilan dasar dan memperoleh informasi yang dapat diajarkan selangkah demi selangkah (Purwanti \& Supriyono, 2018).

Penulis tertarik menganalisis artikel-artikel melalui kajian literatur dikarenakan hingga saat ini masih sedikit peneliti yang melakukan kajian literatur terhadap model pembelajaran langsung dan hasil belajar kognitif siswa sekolah dasar. Selain itu juga, belum adanya penelitian tentang hubungan satu artikel dengan artikel lainnya dengan topik pembahasan yang sama. Kajian literatur merupakan sebuah uraian atau deskripsi tentang literatur yang relevan dengan bidang atau topik tertentu sebagaimana ditemukan dalam buku-buku ilmiah dan artikel jurnal (Lestari, N. \& Riyadi, 2015). Kajian literatur ini memberikan tinjauan mengenai apa yang telah dibahas atau dibicarakan oleh peneliti atau penulis sebelumnya, teori-teori dan hipotesis yang mendukung, permasalahan penelitian yang diajukan atau ditanyakan, metode dan metodologi yang sesuai. Kajian literatur merupakan sebuah uraian atau deskripsi tentang literatur-literatur yang relevan dengan bidang atau topik tertentu. Dalam hal ini mengenai hasil belajar kognitif dengan model pembelajaran langsung.

\section{METODE}

Metode yang digunakan dalam penelitian ini adalah kajian literatur. Kajian literatur merupakan proses umum yang harus kita lalui untuk mendapatkan teori-teori terdahulu. Mencari literatur-literatur yang terkait merupakan tugas yang harus segera dilakukan, kemudian menyusunnya secara teratur dan rapi untuk dipergunakan dalam keperluan penelitian 
(Kharisma, A., 2020). Dalam penyusunan kajian literatur ini melakukan identifikasi secara sistematis, penemuan, dan analisis dokumen-dokumen yang memuat atau berhubungan dengan masalah dalam penelitian yang peneliti lakukan. Kajian literatur merupakan alat yang penting sebagai contect review, karena literatur sangat berguna dan sangat membantu dalam memberi konteks dan arti dalam penulisan yang sedang dilakukan serta melalui kajian literatur ini juga peneliti dapat menyatakan secara eksplisit dan pembaca mengetahui mengapa hal yang ingin diteliti merupakan masalah yang memang harus diteliti, baik dari segi subjek yang akan diteliti dan lingkungan manapun dari sisi hubungan penelitian tersebut dengan penelitian-penelitian lain yang relevan.

Tujuan utama melakukan kajian literatur adalah menemukan variabel-variabel yang akan diteliti, membedakan hal-hal yang sudah dilakukan, dan menentukan hal-hal yang perlu dilakukan, melakukan sintesis dan memperoleh perspektif baru, serta menentukan makna dan hubungan antar variabel. Berdasarkan paparan tersebut, maka peneliti menggunakan kajian literatur dengan menganalisis artikel-artikel ilmiah dari jurnal nasional yang terbit pada tahun 2015 sampai dengan 2020 sebagai metode penelitian agar terlaksananya penelitian yang dimaksud. Tahapan-tahapan yang digunakan pada kajian literatur dapat dilihat pada Gambar 1 berikut:

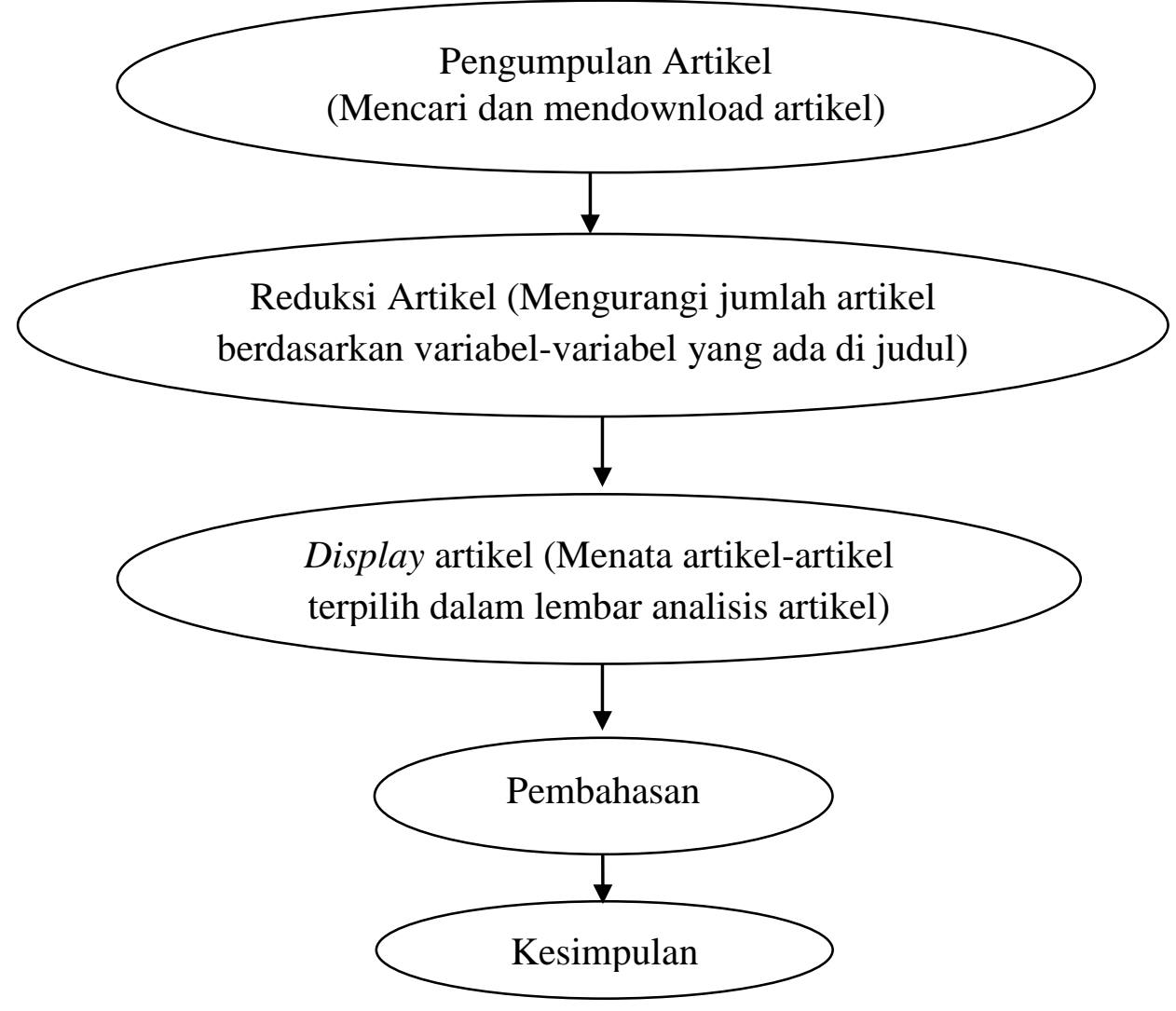

Gambar 1. Tahapan-Tahapan Kajian Literatur (Sumber: (Kurniawan, D., 2020)

\section{HASIL DAN PEMBAHASAN}

Dari 15 artikel didapatkan 4 artikel yang sesuai dengan topik judul. Artikel-artikel hasil belajar kognitif dan model pembelajaran langsung siswa sekolah dasar yang berjumlah 4 artikel didisplay datanya dan dianalisis. Display datanya dapat dilihat pada Tabel 1 berikut: 
Tabel 1. Display Data

\begin{tabular}{|c|c|c|c|c|c|c|}
\hline No. & $\begin{array}{c}\text { Nama Penulis } \\
\text { Artikel }\end{array}$ & $\begin{array}{l}\text { Tahun } \\
\text { Terbit }\end{array}$ & Judul Artikel & Nama Jurnal & $\begin{array}{l}\text { Volume } \\
\text { Nomor }\end{array}$ & $\begin{array}{c}\text { Jumlah } \\
\text { Halaman }\end{array}$ \\
\hline 1 & $\begin{array}{l}\text { 1. Missa. } \\
\text { 2. Hendratno. } \\
\text { ( } 2 \text { orang) }\end{array}$ & 2015 & $\begin{array}{l}\text { Penerapan Model } \\
\text { Pembelajaran } \\
\text { Langsung untuk } \\
\text { Meningkatkan } \\
\text { Hasil Belajar IPA } \\
\text { pada Tema "Sehat } \\
\text { Itu Penting" Siswa } \\
\text { Kelas V SDN } \\
\text { Lidah Wetan II/ } \\
\text { 462 Surabaya. }\end{array}$ & $\begin{array}{l}\text { Jurnal } \\
\text { Universitas } \\
\text { Negeri } \\
\text { Surabaya }\end{array}$ & $\begin{array}{l}\text { Vol. 03, } \\
\text { No. } 02 .\end{array}$ & $\begin{array}{c}10 \\
\text { Halaman } \\
\text { (Hal. } \\
1247- \\
1256)\end{array}$ \\
\hline 2 & $\begin{array}{l}\text { 1. Kurniasih. } \\
\text { (1 Orang) }\end{array}$ & 2016 & $\begin{array}{l}\text { Penerapan Model } \\
\text { Pembelajaran } \\
\text { Langsung untuk } \\
\text { Meningkatkan } \\
\text { Hasil Belajar IPA } \\
\text { Siswa Kelas 1 } \\
\text { SDN 006 TRI } \\
\text { MULYA JAYA. }\end{array}$ & $\begin{array}{l}\text { Jurnal } \\
\text { Primary } \\
\text { Program } \\
\text { Studi } \\
\text { Pendidikan } \\
\text { Guru } \\
\text { Sekolah } \\
\text { Dasar } \\
\text { Fakultas } \\
\text { Keguruan } \\
\text { dan Ilmu } \\
\text { Pendidikan } \\
\text { Universitas } \\
\text { Riau. }\end{array}$ & $\begin{array}{l}\text { Vol. 5, } \\
\text { No. } 3 .\end{array}$ & $\begin{array}{c}13 \\
\text { Halaman } \\
(\text { Hal. } \\
275-287)\end{array}$ \\
\hline 3 & $\begin{array}{l}\text { 1. Arbaatin. } \\
\text { 2. Supriyono. } \\
(2 \text { orang })\end{array}$ & 2015 & $\begin{array}{l}\text { Penerapan Model } \\
\text { Pembelajaran } \\
\text { Langsung untuk } \\
\text { Meningkatkan } \\
\text { Hasil Belajar Tema } \\
\text { Permainan pada } \\
\text { Siswa Kelas I SDN } \\
\text { Mojogeneng } \\
\text { Mojokerto. }\end{array}$ & $\begin{array}{l}\text { Jurnal } \\
\text { Pendidikan } \\
\text { Guru } \\
\text { Sekolah } \\
\text { Dasar }\end{array}$ & $\begin{array}{l}\text { Vol. 03, } \\
\text { No. } 02 .\end{array}$ & $\begin{array}{c}13 \\
\text { Halaman } \\
\text { (Hal. 628- } \\
\text { 640) }\end{array}$ \\
\hline 4. & $\begin{array}{l}\text { 1. Ulifah. } \\
\text { 2. Supriyono. } \\
\text { ( } 2 \text { orang) }\end{array}$ & 2015 & $\begin{array}{l}\text { Penerapan Model } \\
\text { Pembelajaran } \\
\text { Langsung untuk } \\
\text { Meningkatkan } \\
\text { Hasil Belajar d } \\
\text { engan Tema } \\
\text { Peristiwa pada } \\
\text { Siswa Kelas I. }\end{array}$ & $\begin{array}{l}\text { Jurnal } \\
\text { Universitas } \\
\text { Negeri } \\
\text { Surabaya }\end{array}$ & $\begin{array}{l}\text { Vol. 03, } \\
\text { No. } 02 .\end{array}$ & $\begin{array}{c}10 \\
\text { Halaman } \\
\text { (Hal. 651- } \\
660)\end{array}$ \\
\hline
\end{tabular}

Dari ke-4 artikel tersebut nama penulis yang berjumlah 2 orang ada 3 artikel dan penulis yang berjumlah 1 orang terdapat 1 artikel. Tahun terbit artikel hasil belajar kognitif dan model pembelajaran langsung yaitu pada rentang tahun 2015-2020. Artikel yang terbit tahun 2015 berjumlah 3 artikel, artikel yang terbit di tahun 2016 berjumlah 1 artikel. Artikel-artikel hasil 
belajar kognitif membahas tentang tujuan dari hasil belajar kognitif dan model pembelajaran langsung.

Tujuan hasil belajar kognitif dan model pembelajaran langsung terdiri dari 1-4 artikel yang diamati dalam penelitian ini, tujuan hasil belajar kognitif dan model pembelajaran langsung yang diamati dalam proses pembelajaran berjumlah 4 artikel. Jumlah artikel hasil belajar kognitif dan model pembelajaran langsung terdiri dari 7-12 halaman. Artikel dengan 7 halaman terdiri dari 1 artikel, artikel dengan 10 halaman berjumlah 2 artikel, dan artikel dengan 12 halaman terdiri dari 1 artikel.

Hasil belajar kognitif dalam penelitian ini terdiri dari tujuan, akan tetapi setiap artikel tidak mengamati tujuan hasil belajar kognitif yang sama. Setiap artikel memiliki permasalahan yang berbeda sehingga penulis berusaha untuk lebih memahami kepada permasalahan yang diamati dalam proses pembelajaran. Terdapat 3 artikel yang menerapkan aspek hasil belajar kognitif, afektif, dan psikomor (Anggraini et al., 2020). Satu artikel sama dengan aspek yang digunakan oleh peneliti yaitu menerapkan hasil belajar kognitif, yang terdiri dari 6 tingkatan yaitu: mengingat, memahami, menerapkan, menganalisis, menilai, dan menciptakan.

Model pembelajaran langsung terdiri dari langkah-langkah yang bertujuan memudahkan guru dalam menyampaikan materi kepada siswa. Empat artikel terdapat langkah-langkah model pembelajaran langsung. Model pembelajaran langsung dari ke-4 artikel memiliki tahapan dan langkah-langkah yang berbeda. Perbedaan tersebut terlihat pada permasalahan yang berbedabeda langkah-langkah model pembelajaran langsungnya yang dimodifikasi oleh setiap penulis untuk memudahkan masalah pada penelitiannya. Setiap model pembelajaran langsung memiliki langkah-langkah yang berbeda-beda yang disesuaikan dengan materi, serta permasalahan dan situasi tempat penelitian.

Persamaan dari langkah-langkah model pembelajaran langsung dari ke-4 artikel dengan teori yang dirujuk dapat dilihat pada Tabel 2 berikut:

Tabel 2. Persamaan Langkah-Langkah Model Pembelajaran Langsung

\begin{tabular}{|c|l|l|}
\hline No. & $\begin{array}{l}\text { Langkah-Langkah Model Pembelajaran } \\
\text { Langsung menurut Shoimin }\end{array}$ & $\begin{array}{l}\text { Langkah-Langkah Model Pembelajaran } \\
\text { Langsung dari ke 4 artikel yang Dianalisis }\end{array}$ \\
\hline 1 & Orientasi, menyampaikan tujuan. & $\begin{array}{l}\text { Menyampaikan tujuan } \\
\text { mempersiapkan siswa. }\end{array}$ \\
\hline 2 & Presentasi atau demonsrasi. & $\begin{array}{l}\text { Mendemonstrasikan pengetahuan atau } \\
\text { keterampilan. }\end{array}$ \\
\hline 3 & Latihan terbimbing. & Memimbing dan pelatihan. \\
\hline 4 & $\begin{array}{l}\text { Mengecek pemahaman dan memberikan } \\
\text { umpan balik. }\end{array}$ & $\begin{array}{l}\text { Mengecek pemahaman dan memerikan } \\
\text { umpan balik. }\end{array}$ \\
\hline 5 & Latihan mandiri. & $\begin{array}{l}\text { Memberikan kesempatan untuk pelatihan } \\
\text { lanjutan dan penerapan. }\end{array}$ \\
\hline
\end{tabular}

Berdasarkan Tabel 2 tentang persamaan langkah-langkah model pembelajaran langsung, langkah-langkah yang memiliki persamaan terdapat pada nomor 1-5. Persamaan langkahlangkah model pembelajaran langsung ini merupakan langkah-langkah model pembelajaran langsung yang digunakan untuk dapat memudahkan peneliti dalam menyelesaikan masalah penelitiannya. 
Dari ke 4 artikel ini membahas tentang hasil belajar yang mana terdapat 3 ranah hasil belajar yaitu kognitif, afektif, dan psikomotorik. Artikel ini tidak memfokuskan hasil belajar kognitif yang sama. Artikel ini sama-sama menerapkan model pembelajaran langsung yang mana model pembelajaran langsung itu mempunyai langkah-langkah yang digunakan dalam penelitian. Terdapat 2 artikel yang menjelaskan langkah-langkah model pembelajaran langsung, sedangkan 2 artikel tidak menjelaskan langkah-langkah model pembelajaran langsung. Dari ke 4 artikel tersebut hasil penelitiannya mengalami peningkatan. Model pembelajaran langsung ini dapat meningkatkan hasil belajar kognitif Siswa sekolah dasar (Pratama, A., 2018).

Dari hasil penerapan model pembelajaran langsung menunjukan bahwa terdapat peningkatan hasil belajar siswa pada tiap siklus yakni pada siklus I, hasil belajar siswa 56 mengalami peningkatan sebesar 40 pada siklus II menjadi 94, terdapat juga peningkatan aktivitas siswa dalam proses pembelajaran, dimana pada siklus I aktivitas siswa mencapai 69,25\% mengalami peningkatan sebesar 7,75 pada siklus II 85,25. Penelitian ini dilaksanakan sesuai dengan tahapan model pembelajaran langsung dengan berpedoman pada Penelitian Tindakan Kelas (PTK) dengan prosedur penelitian yang terdiri dari perencanaan, pelaksanaan, penggunaan atau observasi dan refleksi. Hasil penerapan model pembelajaran langsung mengalami peningkatan pada setiap siklus pembelajaran yang diperoleh melalui evaluasi yang dilaksanakan pada setiap akhir siklus. Penerapan model pembelajaran langsung dapat meningkatkan hasil belajar organ pencernaan makanan pada manuisa. Oleh karena itu, disarankan agar dalam pembelajaran Ilmu Pengetahuan Alam (IPA) diterapkan model pembelajaran langsung dengan menggunakan media pembelajaran yang sesuai (Sidik, M. \& Winata, 2016).

Pada artikel 2, aktivitas guru pada setiap siklusnya mengalami peningkatan juga, pada siklus I pertemuan I aktivitas guru memperoleh persentase sebesar 37,00\%, pada siklus I pertemuan II meningkat dengan persentase sebesar 50,00\%, pada silus II pertemuan I aktivitas guru mengalami peningkatan dengan persentase sebesar $74,00 \%$ dan pada siklus II pertemuan II meningkat dengan persentase sebesar $82,00 \%$. Aktivitas siswa juga mengalami peningkatan, pada siklus I pertemuan I memperoleh persentase sebesar 37,00\%, pada siklus I pertemuan II meningkat dengan persentase sebesar $41,00 \%$, pada silus II pertemuan I aktivitas siswa mengalami peningkatan dengan persentase sebesar $76,00 \%$ dan pada siklus II pertemuan II meningkat dengan persentase sebesar $80,00 \%$. Hasil belajar IPA siswa juga mengalami peningkatan pada siklus I jumlah siswa yang tuntas hasil belajarnya berjumlah 14 (70,00\%), dan pada siklus II jumlah siswa yang mengalami peningkatan dengan jumlah siswa $17(85,00 \%)$. Begitu pula nilai rata-rata yang diperoleh siswa secara klasikal pada data awal hanya 62 dan setelah siklus I meningkat dengan rata-rata 72.5 setelah siklus II lebih meningkat hingga mencapai ratarata 76,5 (Kurniasih, 2016).

Pada artikel 3, diperoleh kesimpulan bahwa penerapan model pembelajaran langsung tema permainan dapat meningkatkan hasil belajar siswa kelas I di SDN Mojogeneng Mojokerto. Hal ini dibuktikan dengan hal-hal sebagai berikut: (1) aktivitas guru selama penggunaan tema lingkungan dengan menerapkan model pembelajaran langsung mengalami peningkatan. Hal ini ditunjukkan dengan adanya peningkatan persentase aktivitas guru pada siklus I dan siklus II. Aktivitas guru mengalami peningkatan sebesar $12,47 \%$ yaitu dari $78,5 \%$ pada siklus I menjadi $83,33 \%$ pada siklus II. Pengamatan aktivitas guru dalam penggunaan media benda konkret tema permainan dengan penerapan model pembelajaran langsung berjalan dengan baik dan mencapai keberhasilan (Alexander \& Pono, 2019); (2) aktivitas siswa selama kegiatan pembelajaran berlangsung yang menggunakan media benda konkret pada tema permainan 
dengan penerapan model pembelajaran langsung juga mengalami peningkatan. Hal ini dibuktikan dengan adanya peningkatan persentase aktivitas siswa pada siklus I dan siklus II. Peningkatan aktivitas siswa sebesar 13,05\% yaitu dari 78,4 \% pada siklus I menjadi 95,45\% pada siklus II. Pengamatan aktivitas siswa dalam kegiatan pembelajaran yang menggunakan media benda konkret berjalan dengan baik dan lancar serta mencapai keberhasilan; (3) hasil belajar yang diperoleh siswa kelas I di SDN Mojogeneng Mojokerto dengan penggunaan media benda konkret tema permainan mengalami peningkatan. Ketuntasan hasil belajar siswa secara klasikal mengalami peningkatan sebesar $10,92 \%$, yaitu dari $73,26 \%$ siklus I menjadi $84,28 \%$ pada siklus II. Selain itu perkembangan hasil belajar siswa pada aspek psikomotor dan aspek afektif juga mengalami peningkatan. Aspek psikomotor siswa mengalami peningkatan sebesar $4,36 \%$ yaitu dari $76,25 \%$ pada siklus I menjadi $80,61 \%$ pada siklus II. Aspek afektif juga mengalami peningkatan sebesar $8,25 \%$ yaitu dari $76,67 \%$ pada siklus I menjadi $84,92 \%$ pada siklus II. Hasil belajar siswa dari seluruh aspek baik aspek kognitif, aspek psikomotor, maupun aspek afektif telah mencapai keberhasilan.

Pada artikel 4, aktivitas guru dan siswa mengalami peningkatan dari siklus I dan siklus II. Aktivitas guru mengalami peningkatan sebesar 20,8 \% yaitu dari $68,1 \%$ pada siklus I menjadi $88,9 \%$ pada siklus II. Peningkatan aktivitas siswa sebesar $21,4 \%$ yaitu dari $66,1 \%$ pada siklus I menjadi $87,5 \%$ pada siklus II. Data hasil tes siswa pada siklus I mencapai 52\%, dan siklus II mencapai $88 \%$. Dari hasil tersebut dapat disimpulkan bahwa penerapan model pembelajaran langsung dapat meningkatkan hasil belajar tematik pada siswa kelas I SDN Candiharjo I Mojokerto (Marlina \& Marwan, 2015).

\section{UCAPAN TERIMA KASIH}

Tim penulis mengucapkan terima kasih kepada Universitas Pahlawan Tuanku Tambusai dan Program Studi Pendidikan Guru Sekolah Dasar yang telah memberi dukungan terhadap terlaksananya penelitian ini. Tim penulis juga mengucapkan terima kasih kepada Pengelola Jurnal Review Pendidikan dan Pengejaran (JRPP) yang telah memberi review dan masukan atas terbitnya artikel ini.

\section{SIMPULAN}

Berdasarkan hasil kajian literatur tentang hasil belajar kognitif menggunakan model pembelajaran langsung pada siswa sekolah dasar dapat disimpukan bahwa dari 15 artikel yang terbit pada tahun 2015-2020 didapatkan 4 artikel yang sesuai dengan variabel-variabel yang ada dijudul. Model pembelajaran langsung dapat meningkatkan hasil belajar kognitif siswa sekolah dasar.

\section{DAFTAR PUSTAKA}

Alexander, F., \& Pono, F. R. (2019). PENERAPAN METODE PEMBELAJARAN KOOPERATIF TIPE EXAMPLES NON EXAMPLES UNTUK MENINGKATKAN HASIL BELAJAR KOGNITIF SISWA. 1(2), 110-126.

Anggraini, W. N., Purwanto, A., \& Nugroho, A. A. (2020). Peningkatan Hasil Belajar Kognitif Biologi Melalui Problem Based Learning Pada Siswa Kelas X SMA Negeri 1 Bulu Sukoharjo. 2(1), 55-62.

Fatikasari, R., Matius, B., \& Junus, M. (2020). Hasil Belajar Kognitif Peserta Didik Melalui Penerapan Model Pembelajaran Inkuiri Berbantuan Media Simulasi PhET Kelas XI IPA SMA Negeri 1 Anggana Materi Fluida Statis. Jurnal Literasi Pendidikan Fisika, 1(1), 65- 
72.

Hamka, L., \& Arsyad, M. N. (2007). KEEFEKTIFAN PENERAPAN MODEL PEMBELAJARAN LANGSUNG PADA MATERI SISTEM GERAK DI SMA NEGERI 1 DONRI - DONRI.

Kharisma, A., I. (2020). PENGARUH PENGGUNAAN ALAT PERAGA GATOTKACA TERBANG TERHADAP HASIL BELAJAR MATEMATIKA PADA SISWA KELAS III SEKOLAH DASAR. Jurnal JRPP, 3(1), 16-23.

Kurniasih, T. (2016). PENERAPAN MODEL PEMBELAJARAN LANGSUNG UNTUK MENINGKATKAN HASIL BELAJAR IPA SISWA KELAS I SDN 006 TRI MULYA JAYA. Jurnal Primary PGSD, 5(3), 275-287.

Kurniawan, D., A. (2020). PENGGUNAAN MEDIA BELAJAR MONOPOLI UNTUK MENINGKATKAN MOTIVASI DAN HASIL BELAJAR SISWA. Jurnal JRPP, 3(1), $10-15$.

Lestari, N., C., \& Riyadi, A. (2015). PENINGKATAN HASIL BELAJAR KOGNITIF SISWA KELAS X-2 SMAN 1 MUARA PADAMATERI IPA KONSEP EKOSISTEM MENGGUNAKAN MODEL PEMBELAJARAN KOOPERATIF TIPE NHT. Jurnal Cendekia, 9(2), 171-176.

Marlina, \& Marwan, H. (2015). PENGARUH PENERAPAN MODEL PENGAJARAN LANGSUNG (DIRECT INSTRUCTION) TERHADAP HASIL BELAJAR SISWA KELAS X MAN PEUDADA PADA MATERI KEBUTUHAN MANUSIA. JSEE, III(1), $1-10$.

Mulyono, O., Bustami, Y., \& Julung, H. (2017). PENINGKATAN HASIL BELAJAR KOGNITIF SISWA BIOLOGI SEKOLAH MENENGAH PERTAMA MELALUI METODE DEMONSTRASI. JPBIO Jurnal Pendidikan Biologi, 2(2), 15-19.

Pratama, A., T. (2018). PENINGKATAN HASIL BELAJAR KOGNITIF MENGGUNAKAN STRATEGI PEMBELAJARAN PROBLEM BASED LEARNING (PBL) PADA PEMBELAJARAN BIOLOGI DI KABUPATEN DELI SERDANG. Jurnal Biolokus, $1(2), 71-76$.

Purwanti, R., \& Supriyono. (2018). PENERAPAN MODEL PEMBELAJARAN LANGSUNG UNTUK MENINGKATKAN KETERAMPILAN MENULIS DESKRIPSI BAGI SISWA SEKOLAH DASAR. JPGSD, 6(5), 839-848.

Sidik, M., I., \& Winata, H. (2016). Meningkatkan hasil belajar siswa melalui penerapan model pembelajaran direct instruction. Jurnal Pendidikan Manajemen Perkantoran, 1(1), 49-60.

Witarsa, R., Fadhilaturrahmi, \& Rizal, M. S. (2020). Pengaruh Asupan Nutrisi Shake Kacang Kedelai terhadap Skala Lemak Perut Guru-guru Sekolah Dasar di Bangkinang Kota Kabupaten Kampar. Jurnal Basicedu, 3(2), 524-532. 